INRA Prod. Anim.,

2006, $19(5), 327-338$

\title{
La teneur en lipides de la viande : une balance métabolique complexe
}

\author{
F. GONDRETI', J.-F. HOCQUETTE 2 \\ ${ }^{1}$ INRA, Agrocampus, UMR1079 Systèmes d'Elevage, Nutrition Animale et Humaine, \\ F-35590 Saint-Gilles, France \\ 2 INRA, UR1213 Herbivores, F-63122 Saint-Genès Champanelle, France \\ Courriel: Florence.Gondret@rennes.inra.fr
}

\begin{abstract}
La teneur en lipides intramusculaires est un des facteurs clé de l'acceptabilité globale de la viande par le consommateur. Plusieurs résultats récents ont souligné le rôle de la balance entre anabolisme lipidique et catabolisme énergétique dans le muscle, et l'importance du nombre d'adipocytes intramusculaires, dans le déterminisme de la teneur en lipides intramusculaires chez l'animal au stade d'abattage commercial.
\end{abstract}

Les capacités de consommation des produits animaux tendent vers la saturation au sein de l'Union Européenne. Ce phénomène est lié à la satisfaction déjà atteinte des besoins nutritionnels primaires, et à une faible croissance démographique dans la plupart des pays européens (Lossouarn 2003). Il découle également de la liaison établie dans l'esprit des consommateurs entre une consommation excessive de produits carnés et l'augmentation de l'apport alimentaire en graisses notamment saturées (Valsta et al 2005), et de sa relation possible avec certaines pathologies fréquentes dans nos sociétés industrielles (cancers, désordres cardiovasculaires, diabète ou obésité). Enfin, des crises alimentaires successives (Encéphalopathie Spongiforme Bovine (ESB), fièvre aphteuse, grippe aviaire...) fortement médiatisées ont rendu les consommateurs relativement méfiants vis-à-vis de la sécurité sanitaire des produits carnés. C'est pourquoi la maîtrise des qualités sanitaires en premier lieu, mais aussi la garantie d'une certaine homogénéité des produits et l'amélioration de leurs qualités organoleptiques et diététiques sont devenues nécessaires au maintien de la consommation de viande. La quantité de lipides intramusculaires et leur composition en acides gras apparaissent comme des acteurs importants de la genèse des qualités des viandes et des produits issus de leur transformation. En effet, de nombreux consommateurs européens citent le goût, la jutosité, et la présence de gras intramusculaire comme des facteurs clés d'appréciation de la qualité de la viande de porc par exemple (Ngapo et al 2003). Bien que les relations précises entre teneur en lipides intramusculaires et qualités sensorielles soient encore controversées (sans doute du fait de l'existence de valeurs «seuil» pour ces différents paramètres), il est généralement admis que la quantité de lipides dans le muscle influence positivement la flaveur, la jutosité et la tendreté de la viande, ainsi que son acceptabilité globale (Hodgson et al 1991, Fernandez et al 1999). A l'inverse, le dépôt excessif de lipides peut être un facteur de rejet dans l'acte d'achat, car il est souvent associé à une mauvaise image nutritionnelle. Cependant, il ne faut pas oublier que la teneur en lipides des muscles est en fait bien plus faible que celle des pièces de boucherie qui incluent également les dépôts intermusculaires ou sous-cutanés (Culioli et al 2003). En outre, la matière grasse apportée lors de la cuisson contribue largement à la teneur en lipides des viandes cuites directement consommées (Geay et al 2002). Il n'en demeure pas moins que la compréhension du déterminisme de la teneur en lipides dans le muscle reste un sujet de recherche important, en raison de nombreuses incertitudes sur le sujet.

De multiples facteurs contribuent à la variation de la teneur en lipides de la viande crue, comme le génotype, l'alimentation, l'âge, et les conditions d'élevage des animaux, ou l'origine anatomique du muscle (Mourot et Hermier 2001, Wood et al 2004). Cependant, les mécanismes métaboliques qui président à l'établissement de la teneur en lipides intramusculaires restent mal connus malgré de nombreuses recherches effectuées sur ce sujet au cours de ces dernières années. La situation est compliquée par le fait que les lipides recouvrent des composantes chimiques et cellulaires très diverses. Au niveau chimique, les lipides sont soit des phospholipides (ou lipides membranaires de structure), soit des triglycérides (ou lipides de réserve), ces derniers constituant la fraction la plus variable de la teneur en lipides intramusculaires. Au niveau cellulaire, les triglycérides sont stockés pour une part mineure $(5-20 \%)$ dans les fibres musculaires et pour leur plus grande part, dans des cellules spécialisées (les adipocytes) qui se développent le long des faisceaux de fibres (de l'ordre de $80 \%$ des lipides totaux, Essen-Gustavsson et al 1994, Gondret et al 1998). Du fait de la coexistence de ces différents types cellulaires, la teneur en lipides intramusculaire pourrait alors résulter d'un équilibre entre de multiples voies métaboliques actives dans les adipocytes comme dans les fibres musculaires.

L'objectif de cette revue est de faire le point des travaux récemment entrepris à l'INRA chez les mammifères producteurs de viande, et visant à caractériser les voies métaboliques impliquées dans le déterminisme de la teneur en lipides des muscles. Ces recherches ont pu être réalisées par la mise en commun de différentes compétences permettant ainsi une approche plus globale du déterminisme de la teneur en lipides intramusculaires. 


\section{1 / Rappels sur le métabolis- me glucido-lipidique du muscle}

Pour assurer la contraction des fibres musculaires, le muscle doit disposer d'énergie (ATP) fournie par la dégradation de différents substrats énergétiques, captés par et/ou stockés dans le muscle. Le métabolisme énergétique dans le muscle des animaux producteurs de viande a fait l'objet de plusieurs revues récentes (Hocquette et al 2000 par exemple). Globalement, on peut distinguer deux formes principales de génération de l'énergie : la voie anaérobie glycolytique et la voie aérobie oxydative. L'activation préférentielle d'une de ces deux voies est fonction du type de fibres constituant le muscle, de la disponibilité en substrats et en oxygène, et de l'intensité et de la durée de l'exercice physique demandé.
La figure 1 présente les principales composantes du métabolisme énergétique musculaire. Le transport du glucose sanguin à l'intérieur du muscle est ainsi facilité par un transporteur spécifique insulino-dépendant GLUT4, présent à la surface des fibres musculaires et des adipocytes. Le glucose peut être ensuite métabolisé par différentes voies biochimiques. Il peut être converti en glycogène qui est sa principale forme de réserve au niveau musculaire, ou en acides gras grâce à la lipogenèse de novo. Les principales enzymes impliquées dans la synthèse de novo des acides gras sont l'acétyl-CoA carboxylase (ACC) et la synthase des acides gras (FAS), qui interviennent directement dans la conversion de l'acétyl-CoA issu du glucose en acide gras palmitique, et l'enzyme malique et la glucose-6phosphate déshydrogénase (G6PDH) qui fournissent le cofacteur NADPH nécessaire à cette synthèse. Le glucose peut également être partiellement dégradé par la glycolyse anaérobie (dans laquelle intervient notamment la phosphofructokinase ou PFK) et recyclé sous forme de lactate (grâce à l'activité de la lactate déshydrogénase ou LDH). Il peut enfin être complètement oxydé dans les mitochondries par les enzymes du cycle de Krebs (par exemple, la citrate synthase considérée comme un bon marqueur du nombre de mitochondries) puis par les complexes de la chaîne respiratoire (par exemple le complexe IV ou cytochrome-c oxydase).

Les acides gras constituent l'autre substrat énergétique majoritaire du muscle. Les acides gras à chaîne longue transportés par la circulation sanguine se trouvent soit sous forme de triglycérides constituant les lipoprotéines, soit sous forme non estérifiée (acides gras libres liés à l'albumine). L'hydrolyse par la lipoprotéine lipase (LPL) des lipoprotéines riches en triglycérides est

Figure 1. Schéma simplifié du métabolisme glucido-lipique intracellulaire.

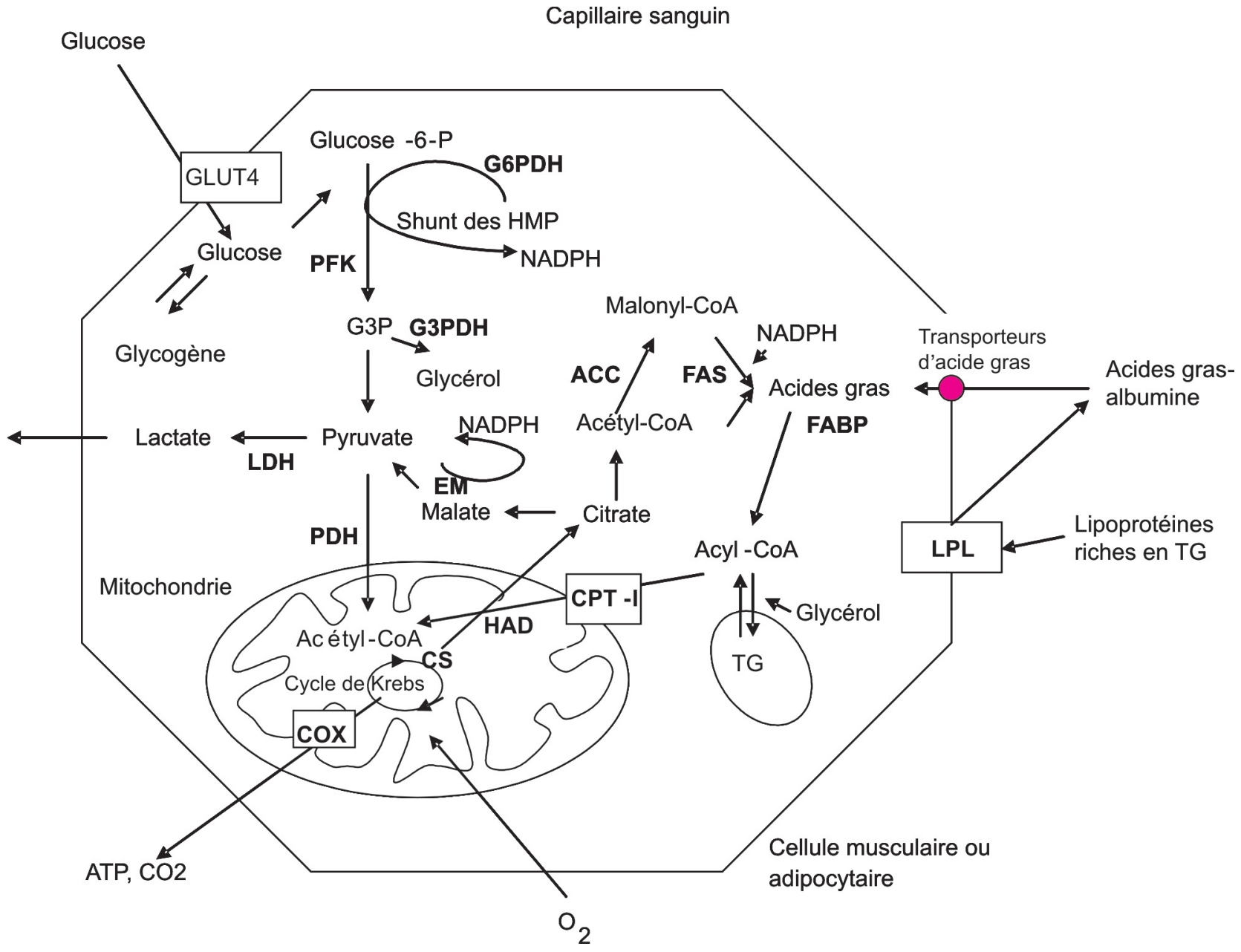

Abréviations : ACC : acétyl-CoA carboxylase ; COX : cytochrome-c oxydase CPT-I : carnitine palmitoyl-transferase-I ; CS : citrate synthase ; EM : enzyme malique ; FABP : protéine de liaison intracellulaire des acides gras (H-FABP : forme musculaire ; A-FABP : forme adipocytaire) ; FAS : synthase des acides gras ; G3PDH : glycérol-3 phosphate déshydrogénase ; G6PDH : glucose-6-phosphate déshydrogénase ; HAD : hydroxyacyl-CoA-déshydrogénase ; HMP : hexoses monophosphates ; LDH : lactate déshydrogénase ; LPL : lipoprotéine lipase ; PDH : pyruvate déshydrogénase ; PFK : phosphofructokinase ; TG : triglycérides 
considérée comme l'étape limitante dans l'utilisation des triglycérides circulants par le muscle. Les acides gras ainsi produits et les acides gras non estérifiés sont internalisés dans le muscle, le passage à travers les membranes plasmiques étant facilité par des transporteurs spécifiques. Au niveau intracellulaire, les acides gras sont liés à des protéines de liaison (parmi lesquelles on trouve les protéines de liaison des acides gras ou FABP pour «fatty acid binding proteins») jusqu'aux sites d'oxydation ou d'estérification. La forme musculaire H-FABP est supposée orienter préférentiellement les acides gras vers les sites d'oxydation intracellulaire. La forme adipocytaire A-FABP est considérée comme un marqueur tardif de la différenciation des adipocytes au cours de l'adipogenèse et donc du nombre d'adipocytes. Dans le muscle, les acides gras peuvent être dégradés dans deux types d'organites : les peroxysomes qui dégradent partiellement les acides gras à chaîne longue jusqu'au stade acétyl-CoA, et les mitochondries responsables de l'oxydation complète des acides gras à chaîne longue ou courte. L'entrée des acides gras dans les mitochondries est sous le contrôle d'une enzyme spécifique, la carnitine palmitoyl-transférase (CPT)-I, considérée comme l'étape limitante de leur oxydation. A l'inverse, les acides gras peuvent aussi être estérifiés en présence de glycérol sous forme de gouttelettes de triglycérides dans le cytoplasme des fibres musculaires ou dans les adipocytes intramusculaires. Le glycérol est obtenu à partir du glucose grâce à l'activité de la glycérol-3phosphate déshydrogénase (G3PDH). Les triglycérides intramusculaires pourront être par la suite dégradés en acides gras à la demande de l'organisme, grâce à l'action de la lipase hormono-sensible (LHS) considérée comme l'enzyme clé de la lipolyse.

Il est admis depuis longtemps qu'il existe une compétition entre l'oxydation des lipides et celle des glucides pour la fourniture de l'énergie à besoins énergétiques constants (Hocquette et al 2000). En effet, le catabolisme des acides gras génère du $\mathrm{NADH}$, de l'ATP et de l'acétyl-CoA qui inhibent la principale enzyme de l'oxydation du glucose, la pyruvate déshydrogénase $(\mathrm{PDH})$, et épargne ainsi les réserves en glycogène musculaire. Réciproquement, une stimulation du catabolisme du glucose diminue l'oxydation des acides gras via l'inhibition de la CPT-I.

\section{2 / Variabilité de la teneur en lipides entre muscles}

La teneur en lipides des muscles est très différente selon la race, le système de production considéré, et pour un même animal, selon le morceau prélevé (c'est-à-dire selon le(s) muscle(s) qui le constituent).

\section{1 / Teneur en lipides et fré- quence des différents types de fibres musculaires}

Au niveau métabolique, on distingue traditionnellement trois types de fibres constituant les muscles : les fibres oxydatives, les fibres oxydo-glycolytiques et les fibres glycolytiques. Au niveau contractile, les fibres sont classées sur la base de leur contenu en isoformes de chaînes lourdes de la myosine I (lente), ou IIa, IIx et IIb (rapides) associées à des vitesses de contraction croissante. Pour la plupart d'entre eux, les muscles sont en fait constitués de proportions variées de ces différents types de fibres, d'où des muscles oxydatifs, oxydoglycolytiques (c'est-à-dire mixtes) ou glycolytiques.

Dans le cas du bovin, force est de constater que les muscles des races originaires des pays anglo-saxons, et surtout du Japon, qui contiennent de 8 à $11 \%$ (pour la catégorie à la note de persillée la plus élevée aux USA) à plus de $20 \%$ de lipides (pour le Bœuf de Kobé au Japon), comportent également une plus grande proportion de fibres oxydatives que ceux des races bovines françaises à maturité physiologique plus tardive, pour lesquelles la plupart des morceaux contient moins de $6 \%$ de lipides avant cuisson (Hocquette 2004). A l'exception de la viande d'agneau, les viandes des autres espèces (porc, lapin, cheval, volailles) sont généralement pauvres en lipides (Culioli et al 2003) ; parallèlement les muscles de ces espèces ont un caractère moins oxydatif que celui des muscles de bovins. Notons cependant que le bison est une espèce aux muscles moins riches en lipides intramusculaires que ceux de bovin, malgré leur caractère plus oxydatif (Agabriel et al 1998).

A côté de ces différences majeures entre espèces, de nombreuses recherches ont porté sur l'étude des relations entre le type de muscle et la teneur en lipides intramusculaires pour un animal donné. Ainsi, il a été observé que les muscles de la partie avant de la carcasse (généralement plus oxydatifs) sont souvent plus riches en lipides que ceux de la partie arrière de l'animal. Par exemple chez le porc, les muscles trapezius et rhomboïdeus contiennent respectivement 5-6\% et 3,5\% de lipides, alors que les muscles longissimus et semimembranosus n'en renferment que 1,5 à $2 \%$ en moyenne. Toutefois, il ne peut être fait de généralisation quant à un éventuel gradient antéropostérieur dans la teneur en lipides intramusculaires. De plus, de nombreux exemples indiquent qu'il n'existe pas de relations simples entre la fréquence des types de fibres musculaires à l'intérieur d'un muscle et sa teneur en lipides intramusculaires. Ainsi, par exemple, chez le porc (Beecher et al 1965, Morrison et Campbell 1971, Wilson et al 1976), la partie rouge oxydative du muscle semitendinosus (composée de fibres de type I pour environ $48 \%$ des fibres) a une teneur en lipides inférieure à celle de la partie blanche glycolytique de ce même muscle (composée d'environ $20 \%$ de fibres de type I). En revanche, il est depuis longtemps admis que les fibres lentes oxydatives contiennent respectivement, 4 et 30 fois plus de triglycérides intracellulaires que les fibres rapides oxydo-glycolytiques de type IIA, et rapides glycolytiques de type IIB/X (Wakata et al 1990 chez le lapin). L'absence de relation entre la teneur en lipides intramusculaires et la fréquence des types de fibres musculaires s'explique par le fait que la majeure partie de la variation de la teneur en lipides entre muscles est en fait liée à des différences dans le nombre d'adipocytes intramusculaires situés entre les faisceaux de fibres (Gondret et al 1998).

\section{2 / Capacité métabolique du muscle et teneur en lipides intra- musculaires : un faux paradoxe}

Chez le bovin et chez le porc, les muscles riches en lipides présentent globalement des capacités intrinsèques élevées pour réaliser la lipogenèse de novo des acides gras puis leur estérification en triglycérides, même si l'ordre de classement entre muscles dans les activités des enzymes impliquées dans ces voies ne suit pas strictement celui rapporté pour leur teneur en lipides intramusculaires (tableau 1). Les muscles riches en lipides totaux se caractérisent globalement par une activité lipoprotéine lipase (LPL) élevée (Hocquette et al 1998), c'est-à-dire par une capacité importante à réaliser l'hydrolyse des lipoprotéines riches en triglycérides qui circulent au niveau sanguin. Cette étape est généralement considérée comme limitante dans le 
Tableau 1. Teneur en lipides intramusculaires et activités de synthèse et d'oxydation des substrats énergétiques entre différents muscles de porc et de bovin.

\begin{tabular}{|c|c|c|}
\hline & PORC & BOVIN \\
\hline Teneur en lipides & $\mathrm{RH}>\mathrm{BF}>\mathrm{LL}$ & $\mathrm{LT}=\mathrm{RA}>\mathrm{ST}^{5}$ \\
\hline $\begin{array}{l}\text { Lipogenèse } \\
\text { ACC ou FAS } \\
\text { Enzyme malique } \\
\text { G6PDH }\end{array}$ & $\begin{array}{l}\mathrm{RH}=\mathrm{BF}>\mathrm{LL} \\
\mathrm{RH}=\mathrm{BF}>\mathrm{LL} \\
\mathrm{RH}>\mathrm{BF}>\mathrm{LL}\end{array}$ & $\begin{array}{l}\mathrm{RA}=\mathrm{ST}^{3} \\
\mathrm{RA}=\mathrm{ST}^{3} \\
\mathrm{RA}>\mathrm{ST}^{3}\end{array}$ \\
\hline $\begin{array}{l}\text { Estérification } \\
\text { G3PDH }\end{array}$ & - & $\mathrm{RA} \leq \mathrm{ST}^{3}$ \\
\hline Hydrolyse des lipides circulants (LPL) & - & $\mathrm{LT}=\mathrm{RA}=\mathrm{ST}^{4}$ \\
\hline $\begin{array}{l}\text { Transport intracellulaire d'acides gras } \\
\text { H-FABP }\end{array}$ & $\mathrm{RH}>\mathrm{BF}=\mathrm{LL}$ & $\mathrm{RA}>\mathrm{ST}^{5}$ \\
\hline $\begin{array}{l}\text { Oxydation des acides gras } \\
\text { HAD }\end{array}$ & $\begin{array}{l}\mathrm{RH}>\mathrm{BF}>\mathrm{LL} \\
\mathrm{RH}>\mathrm{BF}>\mathrm{LL}\end{array}$ & $\begin{array}{l}\mathrm{LT}=\mathrm{RA}^{2} \\
\mathrm{RA}=\mathrm{ST}^{5}\end{array}$ \\
\hline $\begin{array}{l}\text { Oxydation terminale des nutriments } \\
\text { Citrate synthase } \\
\text { Cytochrome-c oxydase }\end{array}$ & - & $\begin{aligned} \mathrm{LT} & =\mathrm{RA}=\mathrm{ST}^{5} \\
\mathrm{LT} & =\mathrm{RA}>\mathrm{ST}^{5}\end{aligned}$ \\
\hline $\begin{array}{l}\text { Glycolyse anaérobie } \\
\text { LDH ou PFK } \\
\text { Potentiel glycolytique }\end{array}$ & $\mathrm{RH}<\overline{\mathrm{BF}}<\mathrm{LL}$ & $\begin{array}{l}\mathrm{LT}=\mathrm{RA}<\mathrm{ST}^{5} \\
\mathrm{RA}<\mathrm{ST} \leq \mathrm{LT}^{1}\end{array}$ \\
\hline
\end{tabular}

* Estimée par la mesure des produits formés au cours de l'oxydation de l'acide oléique marqué. D'après Demeure 2000 chez le porc ; et Talmant et al $1986\left({ }^{1}\right)$. Piot et al $1999{ }^{2}{ }^{2}$,. Bonnet et al $2003\left({ }^{3}\right)$, Hocquette et al $1998\left({ }^{4}\right), 2004$ et données non publiées $\left(^{5}\right)$ chez le bovin.

Abréviations : ACC : acétyl-CoA carboxylase ; BF : biceps femoris ; FAS : synthase des acides gras ; G3PDH : glycérol-3-phosphate déshydrogénase ; G6PDH : glucose-6-phosphate déshydrogénase ; H-FABP : forme musculaire de la protéine de liaison des acides gras ; HAD : hydroxyacyl-CoA déshydrogénase ; LL : longissimus lumborum ; LT : longissimus thoracis ; LDH: Lactate déshydrogénase ; LPL : lipoprotéine lipase ; PFK: Phosphofructokinase ; RA : rectus abdominis ; $\mathrm{RH}$ : rhomboideus ; ST : semitendinosus.

captage et l'utilisation des acides gras par les tissus périphériques (dont le muscle). Toutefois, aucune corrélation significative n'a pu être mise en évidence entre l'activité LPL et la teneur en lipides intramusculaires chez le bovin (Hocquette et al 2003). A l'inverse, les muscles à forte teneur en lipides totaux possèdent souvent une faible activité glycolytique, qu'elle soit estimée par la mesure de l'activité de l'enzyme générant le lactate (LDH) ou par le calcul du potentiel glycolytique musculaire. Enfin, les muscles riches en lipides possèdent globalement une capacité importante à transporter les acides gras vers les sites d'oxydation (capacité mesurée par la quantité ou l'expression de la protéine de liaison intracellulaire H-FABP), puis à les oxyder. Chez le lapin (Gondret et al 2001), une analyse en composantes principales à partir des données recueillies dans trois muscles (semimembranosus proprius, cœur, et longissimus) a permis d'établir un profil métabolique expliquant $50 \%$ de la variation de la teneur en lipides intramusculaires (figure 2). Ce profil est une combinaison linéaire des variables normalisées décrivant la capacité de lipogenèse de novo des acides gras (activités de l'ACC et de la G6PDH), la capacité d'hydrolyse des triglycérides d'oxydation des substrats (activités des enzymes HAD, citrate synthase, et COX), opposées au métabolisme glycolytique anaérobie (activité de la PFK). Cette opposition entre la capacité d'oxydation des acides gras et le niveau de la glycolyse anaérobie dans le muscle reflète très certainement la compétition entre substrats dans la fourniture de l'énergie. La seule capacité du muscle à stocker l'énergie sous forme de lipides, mesurée par les activités de la LPL et des enzymes de la lipogenèse, n'explique que $3 \%$ de la variabilité de la teneur en lipides entre muscles lorsqu'elle est considérée isolément de sa capacité oxydative (Gondret et al 2001).

En résumé, les muscles les plus riches en lipides sont donc ceux qui synthétisent plus d'acides gras in situ mais aussi ceux qui utilisent d'avantage les acides gras comme fournisseurs d'énergie pour la contraction des fibres musculaires. Ce paradoxe apparent suggère que les différences de teneurs en lipides entre muscles de la carcasse sont liées à l'importance plus ou moins grande des flux de lipides dans le muscle. En accord, des études chez le rat ont montré par utilisation de traceurs radioactifs que les triglycérides du muscle sont soumis à un turnover rapide (Dyck et al 1997, Guo et Jensen, 1998). La teneur en lipides plus élevée dans un muscle par rapport à un autre s'expliquerait alors par une capacité à de liaison H-FABP) et la capacité

Figure 2. Relation entre la teneur en lipides de trois muscles prélevés chez des lapins de race Blanc Néo-zélandais et leur profil métabolique glucido-lipidique (Gondret et al 2001).

$R^{2}=0,50$

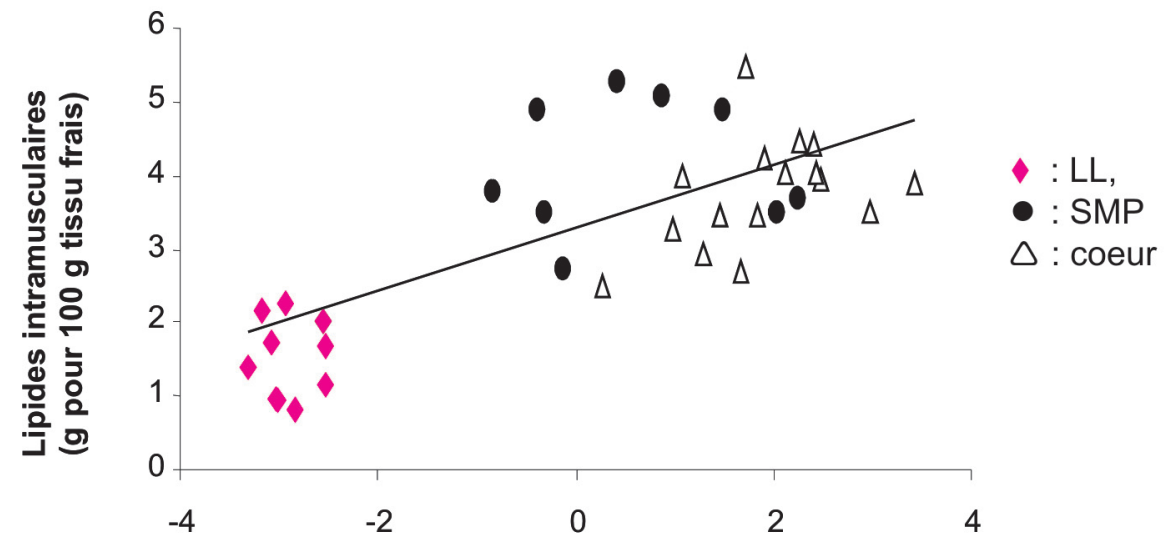

Valeur du profil métabolique (unités arbitraires)

Composition mathématique du profil métabolique ${ }^{1}$ :

$Y=0.32 \mathrm{G} 6 \mathrm{PDH}+0.28 \mathrm{ACC}+0.37 \mathrm{LPL}+0.37[\mathrm{H}-\mathrm{FABP}]+0.35 \mathrm{HAD}+0.40 \mathrm{CS}+0.38 \mathrm{COX}-0.32 \mathrm{PFK}$

1 Les différentes variables après normalisation contribuent de manière équivalente à la définition du profil. Abréviations : ACC: acétyl-CoA carboxylase ; COX : cytochrome-c oxydase ; CS : citrate synthase G6PDH : glucose-6-phosphate déshydrogénase ; HAD : hydrocy-acylCoA déshydrogénase ; H-FABP : forme musculaire de la protéine de liaison intracellulaire d'acides gras; LL : longissimus lumborum : LPL : lipoprotéine lipase ; PFK : phosphofructokinase ; SMP : semimembranosus proprius. 
déposer les acides gras en excès par rapport à la capacité propre du muscle à les oxyder.

\section{3 / Variabilité de la teneur en lipides au sein d'un même muscle en fonction du développement physio- logique des animaux}

\section{1 / Effet de l'âge et du poids des individus}

Le dépôt de lipides dans le muscle se produit tardivement au cours de la croissance de l'animal. Chez le jeune animal, les triglycérides sont principalement localisés à l'intérieur des fibres musculaires. L'augmentation simultanée du poids et de l'âge s'accompagne généralement d'une augmentation de la teneur en lipides intramusculaires chez le porc comme chez le lapin (figure 3 ), et des résultats similaires ont été obtenus chez le bovin en croissance (Pethick et al 2005). L'accumulation de lipides dans le muscle est parallèle à une augmentation du nombre et de la taille des adipocytes intramusculaires chez le lapin (Gondret et al 1998), le porc (Chora 1996) et le bovin (Nicastro et al 2000). La cinétique de dépôt de ces lipides est cependant fonction du génotype des animaux mais aussi du muscle considéré. Par exemple chez le porc, l'accumulation des lipides avec la croissance est plus prononcée dans le muscle latissimus dorsi que dans le muscle biceps femoris (Kauffman et Safanie 1967). Certains auteurs n'observent pas de variation significative de la teneur en lipides chez l'animal en croissance, probablement du fait d'une hétérogénéité dans les sites de prélèvements (Link et al 1970) ou de variation dans le régime alloué aux animaux au cours de la période d'engraissement.

Figure 3. Evolution de la teneur en lipides du muscle longissimus au cours de la croissance en fonction de l'espèce (les types génétiques sont indiquées entre parenthèses).

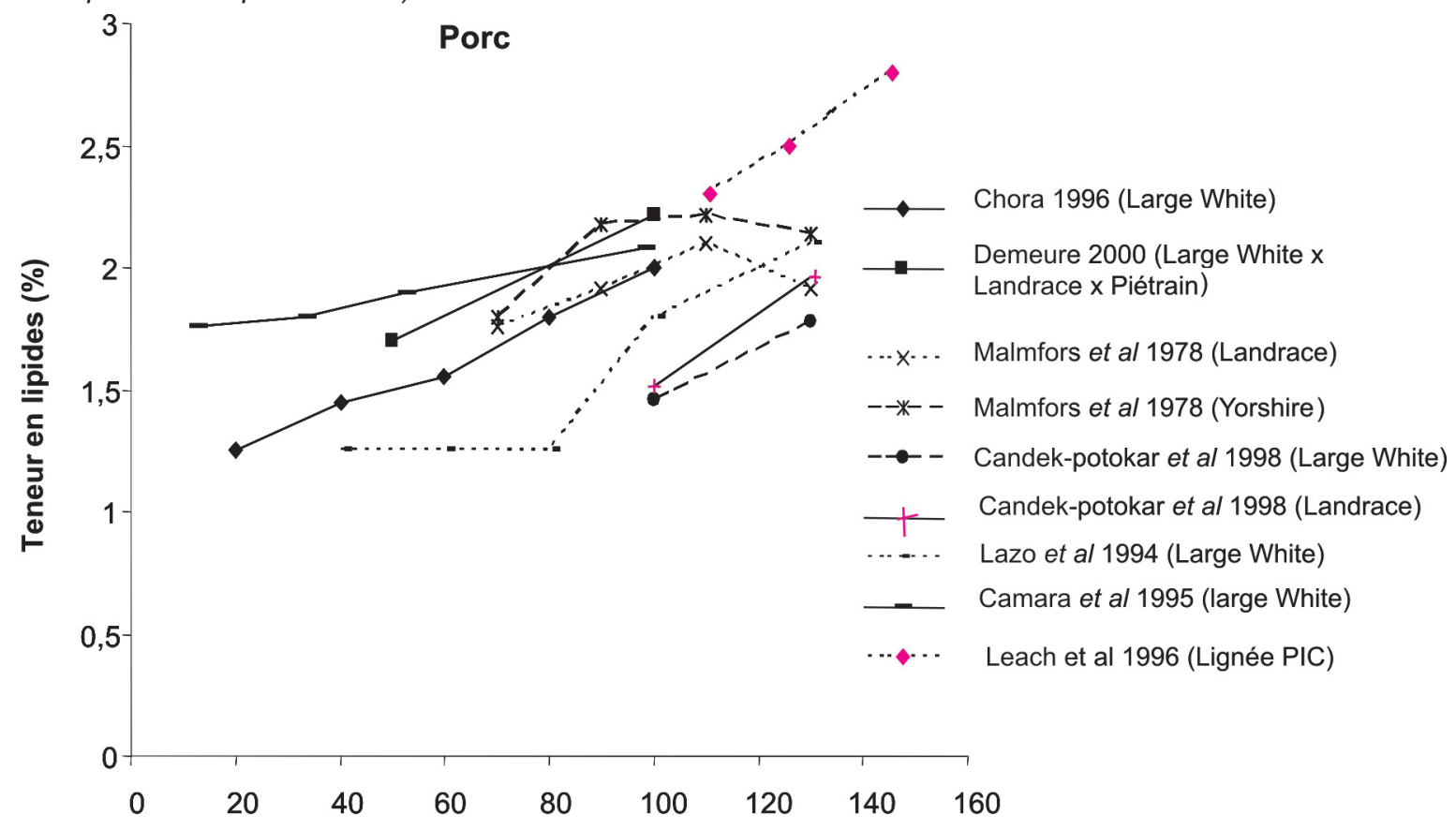

Poids vif (kg)

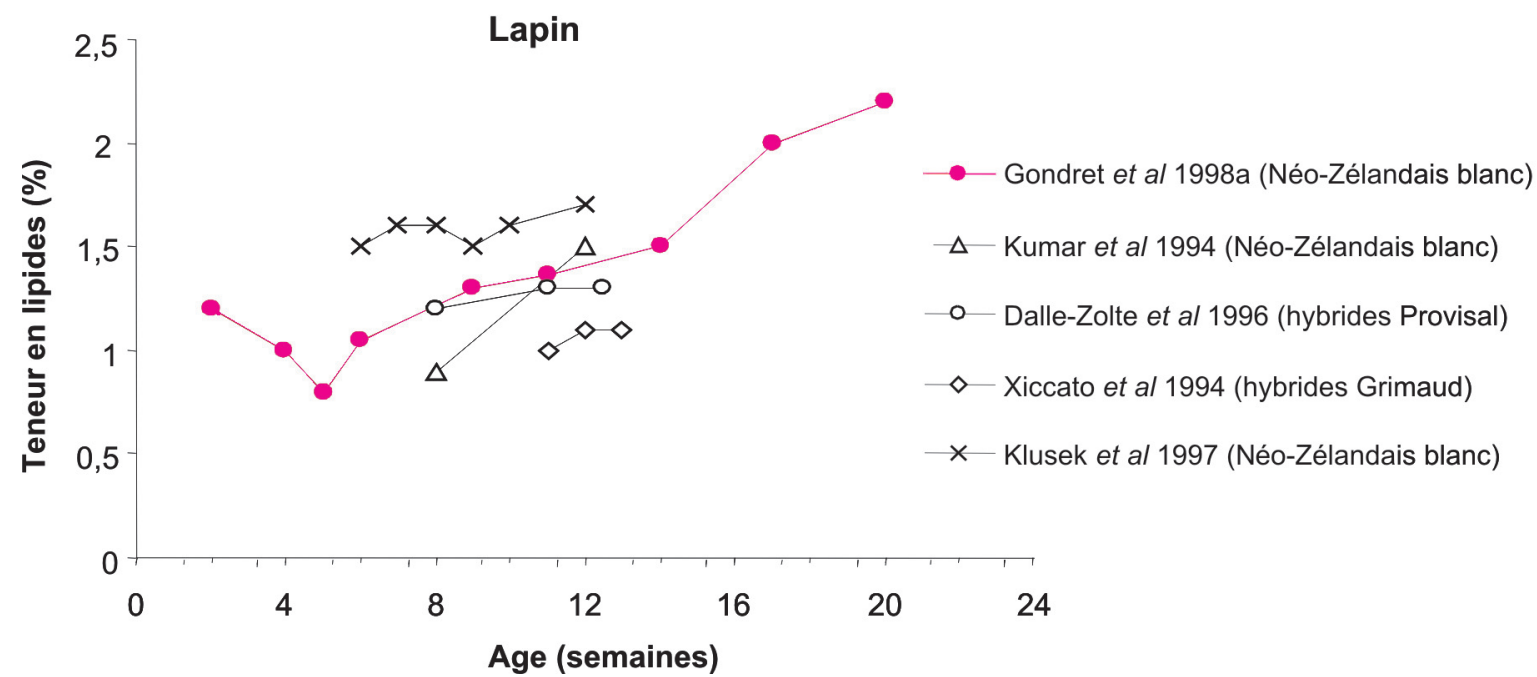




\section{2 / Balance métabolique et accumulation des lipides avec la croissance}

Compte tenu de la complexité du métabolisme énergétique musculaire, il semble illusoire de vouloir appréhender le déterminisme de la teneur en lipides intramusculaires par la simple mesure d'une seule voie métabolique. Chez le lapin, Gondret et al (2004) ont réalisé une analyse en composantes principales à partir de variables mesurées dans le muscle longissimus, mais aussi dans le plasma (source de substrats énergétiques), dans le tissu adipeux et dans le foie (sites majeurs respectivement, de la synthèse lipidique et de l'oxydation). Cette analyse a permis de définir un profil métabolique dont l'évolution au cours de la croissance est responsable de $68 \%$ de la variation de teneur en lipides intramusculaires (figure 4 ) entre l'âge de 10 semaines $(2,4 \mathrm{~kg}$ environ) et 20 semaines $(4,3 \mathrm{~kg}$ environ). Cette approche démontre ainsi mathématiquement que l'élévation de la teneur en lipides du muscle au cours de la croissance de l'animal est liée à l'orientation du métabolisme musculaire vers une capacité lipogénique supérieure, mais aussi vers une diminution des capacités de transport intracellulaire des acides gras (quantité de protéine de liaison H-FABP) et de l'oxydation mitochondriale des nutriments (HAD et citrate synthase). De manière surprenante, l'activité de la cytochrome-c oxydase, enzyme de l'oxydation terminale des nutriments, est reliée positivement à la teneur en lipides intramusculaire dans le muscle longissimus du lapin en croissance. Il est intéressant de noter qu'une relation similaire a été observée chez le bovin, cette fois lorsque l'on compare pour un même muscle des individus au potentiel génétique de dépôt de lipides différent (figure 5A).

L'accumulation des lipides au sein d'un muscle au cours de la croissance de l'animal résulte donc là encore d'une modification de la balance métabolique entre synthèse et catabolisme des acides gras en faveur de l'anabolisme, et non de la régulation d'une seule voie métabolique. La seule mesure de l'activité d'une enzyme impliquée dans la synthèse des acides gras comme celle d'un indicateur de l'oxydation mitochondriale, est donc insuffisante pour comprendre et prédire l'évolution de la teneur en lipides intramusculaires au cours de la croissance. Cette situation rend donc compliquée toute volonté d'orienter le dépôt de lipides dans le muscle par voie nutritionnelle par exemple.
Figure 4. Relation entre la teneur en lipides dans le muscle longissimus et le métabolisme glucido-lipidique du muscle chez des lapins de race Blanc Néo-zélandais entre 10 et 20 semaines d'âge (Gondret et al 2004).

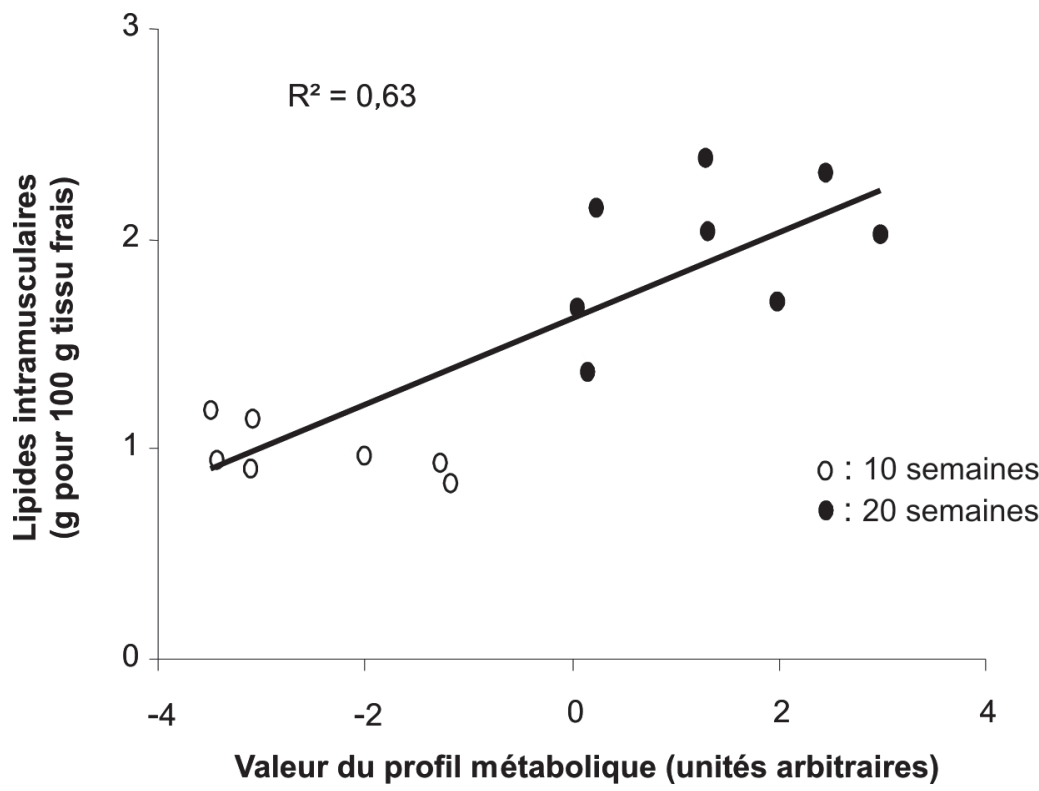

Composition mathématique du profil métabolique ${ }^{1}$

$\mathrm{Y}=0.22 \mathrm{ACC}+0.35 \mathrm{EM}+0.27 \mathrm{G} 6 \mathrm{PDH}+0.34 \mathrm{COX}-0.36 \mathrm{LPL}-0.29[\mathrm{H}-\mathrm{FABP}]-0.33 \mathrm{HAD}-0.37 \mathrm{CS}$ $+0.24[\mathrm{PC} A \mathrm{AG}]-0.28\left[\mathrm{PC}_{\text {glucose }}\right]$

1 Les différentes variables après normalisation contribuent de manière équivalente à la définition du pro-

Abréviations : ACC : acétyl-CoA carboxylase ; EM : enzyme malique ; G6PDH : glucose-6-phosphate déshydrogénase (enzymes de la lipogenèse) ; CS : citrate synthase (régulateur de l'activité des enzymes lipogéniques); LPL : lipoprotéine lipase (hydrolyse des triglycérides circulants et prélèvement des acides gras produits) ; H-FABP : transporteur intracellulaire d'acides gras, forme musculaire $\mathrm{HAD}$ : hydroxyacyl-CoA-déshydrogénase (enzyme de l'oxydation des acides gras) ; COX : cytochrome oxydase (enzyme de la chaîne respiratoire) ; $\mathrm{PC}_{\mathrm{AGL}}$ : concentration plasmatique en acides gras libres, intégrant les métabolismes du foie et du tissu adipeux ; $\mathrm{PC}_{\text {glucose }}$ : concentration plasmatique en glucose, intégrant l'activité lipogénique du foie.

Figure 5. Relation entre l'activité cytochrome-c oxydase ou la quantité de protéine de liaison des acides gras adipocytaire (A-FABP), et la teneur en lipides intramusculaires chez le bovin et le porc.

A - Races bovines Angus, croisés Noir Japonais x Angus ( $N J x A)$ et Limousine présentant une différence importante de teneur en lipides dans les muscles rectus abdominis (RA), semitendinosus (ST) et longissimus thoracis (LT) (Hocquette et al 2003).

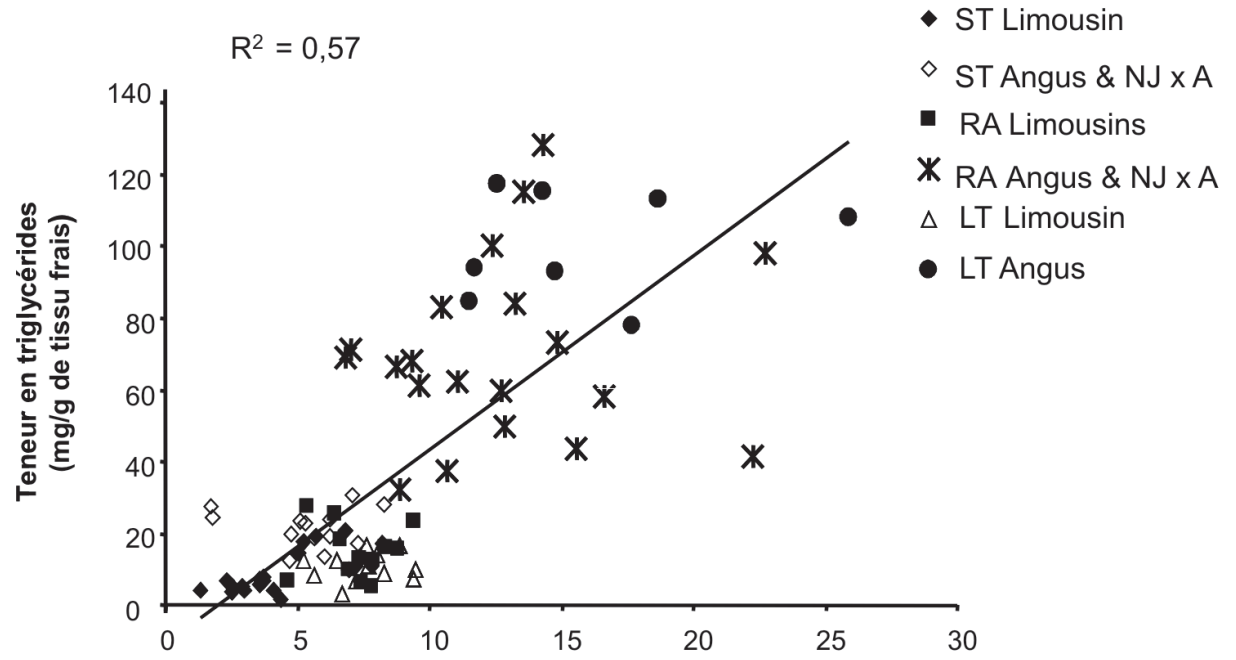

Activité de la cytochrome-c oxydase (unités par $\mathbf{g}$ de tissu frais) 


\section{4 / La balance métaboli- que explique-t-elle tout ? Exemple de l'effet du type génétique des animaux}

\section{1 / Potentiel génétique et teneur en lipides intramusculai- res}

Il existe de grandes différences dans la teneur en lipides intramusculaires selon le type génétique des animaux. Chez le porc par exemple, les races chinoises (Meishan) et américaines (Duroc) présentent des teneurs en lipides de la viande plus élevées que celles rencontrées dans les génotypes européens (Large White, Landrace, ou Piétrain, Sellier 1998). Chez le bovin, les individus de race Angus et surtout Noire Japonaise ont une teneur en lipides musculaires et une note de persillée bien supérieures à celles des animaux de races européennes Holstein, Charolaise, et surtout Blanc Bleu Belge (Zembayashi et Lunt 1995, Hocquette et al 2004). Compte tenu de la corrélation génétique certes modérée mais néanmoins positive entre la teneur en lipides intramusculaires et l'adiposité de la carcasse (Sellier 1998), il semble alors difficile de sélectionner simplement des individus sur la teneur en lipides intramusculaires sans accroître en même temps l'adiposité globale de l'animal. Ces observations ont depuis longtemps conduit les scientifiques à rechercher si des gènes spécifiques pouvaient être à l'origine de la variation de teneur en lipides de la viande. L'incidence d'un gène à effet majeur sur la teneur en lipides intramusculaires (MI pour Meishan Intramuscular fat gene) mais sans effet marqué sur l'adiposité de la carcasse, a été démontrée dans une population de porcs croisés entre races européennes et chinoises (Janss et al 1997), mais son existence reste encore à identifier pour les autres génotypes porcins. Une dizaine à une vingtaine de loci ou QTL (Quantitative Trait Loci) a été également identifiée sur différents chromosomes comme impliqués dans la variabilité de la teneur en lipides intramusculaires ou de persillé de la viande, respectivement chez le porc (Bidanel et Rothschild 2002, Stearns et al 2005) et chez le bovin (Kühn et al 2005). Certains de ces QTL présenteraient une liaison positive avec la teneur en lipides intramusculaires et le gras périviscéral (c'est-à-dire les dépôts de gras «internes») indépendamment de la quantité de gras sous-cutané chez le porc
(Gilbert et al 2004). Pour l'ensemble de ces QTL, il reste cependant à identifier les gènes impliqués.

\section{2 / L'hyperplasie adipocytai- re : phénomène majeur de la va- riabilité génétique de la teneur en lipides intramusculaires ?}

Chez le bovin, différents auteurs ont montré que les différences de teneur en lipides entre les races Angus, Limousine et Blanc Bleu Belge s'expliquent pour $33 \%$ à $47 \%$ par des différences d'activité de la cytochrome-c oxydase, plus élevée dans la race à forte teneur en lipides intramusculaires (Hocquette et al 2003, Barnola et al 2005, figure 5A). Cependant, l'activité de cette enzyme s'avère inadaptée pour prédire la variabilité individuelle de la teneur en lipides intramusculaires au sein d'une race bovine donnée (Barnola et al 2005). En outre, les indicateurs métaboliques précédemment mis en exergue chez le lapin (cytochrome-c oxydase, mais aussi H-FABP, HAD, et citrate synthase) sont exprimés de manière comparable dans les muscles semitendinosus de taurillons Charolais issus d'une sélection divergente pour le potentiel de croissance, malgré une différence de l'ordre de $20 \%$ dans la teneur en lipides intramusculaires (Hocquette et al 2004). Seules les activités de la cytochrome-c oxydase et de la citrate synthase sont réduites dans le muscle rectus abdominis des taurillons à fort potentiel de croissance et faible teneur en lipides intramusculaires, comparativement à leurs congénères sélectionnés pour une faible croissance musculaire. Enfin, deux groupes de porcs croisés Duroc x Large White constitués

B - Population de porcs croisés Duroc $x$ Large White présentant une différence importante de teneur en lipides dans le muscle longissimus lumborum (Damon et al 2006).

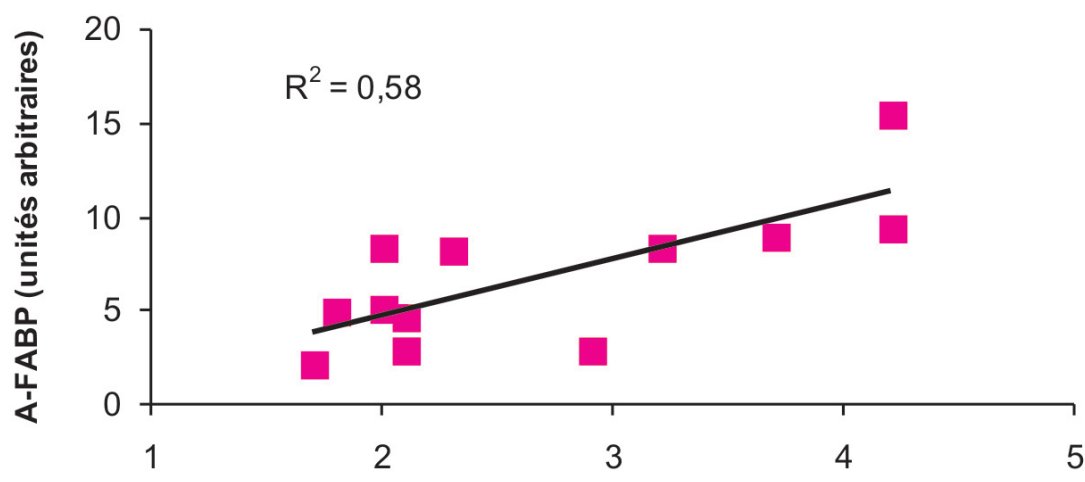

Lipides intramusculaires ( $\mathrm{g} / 100 \mathrm{~g}$ de tissu frais) au cours de deux générations successives sur la base de la teneur en lipides du muscle longissimus ne présentent pas de différences dans les activités des principales enzymes de la lipogenèse ou de l'oxydation mitochondriale des nutriments, et dans la quantité de protéine H-FABP (Damon et al 2006).

Force est donc de conclure que la balance métabolique intramusculaire identifiée comme étant à l'origine de la variation de la teneur en lipides intramusculaires au cours de la croissance ou entre muscles d'un animal donné, s'avère insuffisante pour rendre compte de la variabilité génétique. Ce paradoxe serait lié au fait que la majeure partie des différences entre les animaux à fort ou faible potentiel génétique de dépôt de lipides intramusculaires résulte de différences dans le nombre d'adipocytes présents dans le muscle de l'animal, que ce soit chez le porc (Damon et al 2006) ou le bovin (Cianzo et al 1985). En conséquence, la sélection génétique prédisposerait à une hyperplasie adipocytaire prolongée qui serait le mécanisme principal expliquant les différences de teneurs en lipides intramusculaires. En faveur de cette hypothèse, une relation positive a été identifiée entre la variation génétique de la teneur en lipides intramusculaires chez le porc et le bovin, et la quantité de protéine de liaison A-FABP considérée comme un marqueur de l'adipogenèse (Hocquette et al 2003, Barnola et al 2005, Damon et al 2006, figure 5B). Cette variation dans la quantité de protéine A-FABP dans le muscle expliquerait ainsi $58 \%$ de la variabilité de la teneur en lipides intramusculaires entre races bovines Angus et Limousine, et croisés Angus x 
Noir Japonais (Hocquette et al 2003), et de $53 \%$ à $78 \%$ de la variabilité de ce caractère dans le muscle longissimus de porcs croisés Duroc x Large White présentant une teneur élevée ou faible en lipides intramusculaires (Damon et al 2006). Ce paramètre est plus aisément mesurable dans le muscle que le nombre d'adipocytes qui nécessite des mesures histologiques longues, ou que la teneur en lipides totaux qui nécessite souvent une quantité importante d'échantillon. Cependant, un certain nombre de difficultés au moins d'ordre technique limite l'utilisation de la A-FABP comme critère de sélection ou de discrimination. D'une part, les protéines de liaison des acides gras peuvent être régulées de manière post-transcriptionnelle. D'autre part, les méthodes disponibles à ce jour n'ont pas toutes la même sensibilité ou la même reproductibilité. Pour l'une ou l'autre de ces raisons, aucune différence significative dans la quantité d'ARNm codant pour la A-FABP n'a été observée entre taurillons Charolais sélectionnés de manière divergente sur la vitesse de croissance, en dépit de leur différence de teneur en lipides intramusculaires (Hocquette et al 2004). De même, Damon et al (2006) n'observent pas de relation entre la quantité d'ARNm de la A-FABP et la teneur en lipides intramusculaires chez des porcs croisés Duroc x Large White. Il est donc plus judicieux de déterminer directement la quantité de protéine A-FABP par exemple par un test de type ELISA, mais cela nécessite de disposer d'un anticorps réellement spécifique, ce qui n'est pas le cas chez toutes les espèces. Enfin, l'ensemble des données concernant la relation entre la quantité de protéine A-FABP et la teneur en lipides intramusculaires a été obtenu pour un nombre limité de génotypes et d'animaux. Or, Gerbens et al (2001) n'identifient pas de relation significative entre la quantité de protéine A-FABP et la teneur en lipides intramusculaires chez des porcs croisés Large White $\mathrm{x}$ Landrace, vraisemblablement parce que la population choisie n'a pas le bon allèle en ségrégation. L'intérêt potentiel de la A-FABP comme marqueur précoce de la teneur en lipides intramusculaires doit donc être estimé sur un nombre plus important de modèles animaux.

\section{5 / De nouvelles recherches sur la teneur en lipides
intramusculaires}

\section{1 / Recherches de gènes candi- dats}

En parallèle à la recherche de QTL, plusieurs gènes ont été identifiés comme candidats vis-à-vis du contrôle de la teneur en lipides de la viande. Ainsi, Gerbens et al (2000) ont suggéré l'implication d'un polymorphisme au niveau du gène de la protéine de liaison musculaire H-FABP chez le porc. Cependant, une telle association entre la quantité de protéine H-FABP et la teneur en lipides intramusculaires n'a pas été retrouvée dans les études ultérieures chez cette même espèce (Gerbens et al 2001, Damon et al 2006). Une relation positive a également été mise en évidence entre la teneur en lipides du muscle et l'activité de l'enzyme malique, identifiée comme le principal fournisseur de NADPH pour la lipogenèse des acides gras chez le porc (Mourot et Kouba 1998). Chez le bovin (Kühn et al 2005), des associations significatives entre l'augmentation de la teneur en lipides intramusculaire et un allèle d'un gène particulier ont été également mises en évidence, notamment pour la thyroglobuline (précurseur de deux hormones thyroïdiennes), ou la diacylglycérol-O-acyltransférase (impliquée dans l'estérification des acides gras en triglycérides). Cependant, d'autres auteurs ne confirment pas ces observations dans divers modèles animaux (Middleton et al 1998, Damon et al 2006). Enfin, un polymorphisme du facteur de transcription mitochondrial A (TFAM) qui régule la transcription et la réplication de l'ADN mitochondrial, a été associé à la fois à la note de persillé et à l'épaisseur de gras sous-cutané chez des bovins Wagyu x Limousin (Jiang et al 2005). Son implication éventuelle dans d'autres races bovines comme chez d'autres espèces de mammifères reste à étudier.

\section{2 / De nouvelles pistes grâce à la génomique ?}

L'ensemble des données disponibles renforce ainsi l'hypothèse d'un déterminisme très complexe de la teneur en lipides intramusculaires. Cette dernière semble ainsi être la résultante à la fois d'un turnover élevé des acides gras dans le muscle, de l'orientation d'une balance métabolique en faveur de processus conduisant au stockage des acides gras dans les adipocytes intramusculaires aux dépens de leur utilisation dans les fibres musculaires, mais aussi à la capacité de prolifération et de différenciation des adipocytes intramusculaires. Une analyse exhaustive et surtout sans a priori qui consisterait à identifier de nouveaux gènes dont l'expression varie avec la teneur en lipides de la viande, devrait alors permettre d'en mieux comprendre le déterminisme.

L'analyse du transcriptome permet d'envisager l'expression d'un grand nombre de gènes présents à un instant donné dans un tissu, et ainsi d'identifier des nouveaux gènes ou des groupes de gènes dont l'expression est reliée à la caractéristique d'intérêt. A titre d'exemple, différentes études ont permis de caractériser le profil global $d$ 'expression des gènes entre différents types de muscles chez le porc (Wimmers et al 2005) et le bovin (Sudre et al 2003 par exemple). De plus, des équipes coréenne (Cho et al 2002) et australienne (revue de Lehnert et al 2006) ont identifié des gènes candidats pour le contrôle de l'accumulation des lipides chez le bovin, à l'aide de micro-réseaux constitués de gènes de muscle et de gènes de tissu adipeux. Par exemple, Wang et al (2005) ont confirmé par des approches transcriptomiques l'expression différentielle dans le muscle de la A-FABP entre races bovines produisant des viandes riches ou pauvres en lipides intramusculaires. Enfin, TePas et al (2005) ont récemment utilisé des micro-réseaux porcins constitués de 306 cDNA de muscles squelettiques afin de comparer le développement musculaire entre génotypes Duroc et Piétrain. Ils démontrent ainsi que les deux génotypes, qui présentent une teneur en lipides intramusculaires respectivement élevée et faible au stade commercial d'abattage, se caractérisent dès le 14ème jour de gestation par des différences dans le profil d'expression des gènes impliqués dans le métabolisme des acides gras. Ces données renforcent ainsi l'hypothèse d'un déterminisme précoce dans l'accumulation des lipides musculaires entre types génétiques. Des programmes sont également en cours à l'INRA visant à caractériser le transcriptome du muscle mais aussi des adipocytes intramusculaires isolés chez le porc et/ou le bovin, en relation avec la variation génétique de la teneur en lipides intramusculaires. Dans cet objectif, des collections d'ADNc bovin et porcin issues de banques multi-tissus (programme AGENAE pour Analyse du GENome 
des Animaux d'Elevage), ou de muscles cardiaque et squelettiques (Sudre et al 2005 pour le muscle de bovin), sont en cours de caractérisation ou d'exploitation.

Si les protéines proviennent de la traduction des ARNm, considérer le profil protéique (ou protéome) comme le reflet exact du transcriptome est une approximation. En effet, un même ARNm peut donner plusieurs protéines différentes, plus ou moins actives s'il s'agit d'enzymes. Des cartographies protéiques détaillées du muscle semitendinosus de bovin (Bouley et al 2004) et du muscle longissimus de porc (Morzel et al 2004) ont été récemment établies. De même, nous avons récemment établi une spécificité certaine du profil protéique des adipocytes intramusculaires (muscle trapezius) chez le porc par rapport aux adipocytes isolés de tissus adipeux sous-cutanés
(Gondret et al 2006). Cette approche devrait fournir à terme de nouveaux marqueurs permettant de mieux comprendre la relation entre l'environnement cellulaire, la fonctionnalité des adipocytes, et la teneur en lipides.

L'association de ces deux approches de génomique fonctionnelle permettra dans un avenir proche de suivre au plus près le fonctionnement du muscle et de ses cellules constitutives. Elle devrait permettre à terme de mieux comprendre le déterminisme de la variabilité de la teneur en lipides intramusculaires et/ou d'identifier de nouveaux prédicteurs de cette variabilité.

\section{Conclusion}

La teneur en lipides intramusculaires des animaux producteurs de viande apparaît donc comme une caractéris- tique dont les déterminismes génétique et métabolique restent très complexes. De ce fait, toute stratégie visant à moduler la teneur en lipides du ou des muscle(s) avant l'abattage de l'animal ne peut probablement pas être basée sur le contrôle d'un gène particulier ou d'une voie métabolique unique. Les approches de transcriptomique et de protéomique sont actuellement en plein essor. Elles devraient permettre aux scientifiques de trouver de nouveaux marqueurs ou ensemble de caractéristiques fonctionnelles associées à la teneur en lipides intramusculaires. A terme, il s'agira de proposer des solutions afin d'assurer une viande de qualité constante et d'en améliorer les caractéristiques sensorielles.

\section{Références}

Agabriel J., Bony J., Micol D., 1998. Le bison d'Amérique. Elevage, production et qualité de la viande. INRA (Ed), Paris, France, 106p.

Barnola I., Hocquette J.F., Cassar-Malek I., Jurie C., Gentès G., Cabaraux J.F., Cuvelier C., Istasse L., Dufrasne I., 2005. Adipocyte fatty acid-binding protein expression and mitochondrial activity as indicators of intramuscular fat content in young bulls. In: Indicators of milk and beef quality. Hocquette J.F., Gigli S. (Eds). EAAP Publication, 112. Wageningen Pers, Wageningen, The Netherlands, 419-424.

Beecher G.R., Cassens R.G., Hoekstra W.G., Briskey E.J., 1965. Red and white fiber content and associated post-mortem properties of seven porcine muscles. J. Food Sci., 30, 969-976.

Bidanel J.P., Rothschild M., 2002. Current status of quantitative trait locus mapping in pigs. Pig News Inf., 23, 39N-54N.

Bonnet M., Faulconnier Y., Hocquette J.F., Leroux C, Boulesteix P., Chilliard Y, Pethick D.W., 2003. Lipogenesis in subcutaneous adipose tissue and in oxidative or glycolytic muscles from Angus, Black Japonese x Angus, and Limousin steers. In: Progress in Research on Energy and Protein Metabolism. Souffrant W.B., Metges C.C. (Eds). EAAP Publication, 109. Wageningen Pers, Wageningen, The Netherlands, 469-472.

Bouley J., Chambon C., Picard B., 2004. Mapping of bovine skeletal muscle proteins using two-dimensional gel electrophoresis and mass spectrometry. Proteomics, 4, 1811-1824.

Camara M. 1995. Développement morphologique et métabolique des couches du tissue adipeux sous-cutané dorsal chez le porc : influences de l'âge, de la race et des matières grasses. Thèse de l'Université Paris VII, $124 \mathrm{p}$.

Candek-Potokar M., Zlender B., Lefaucheur L., Bonneau M. 1998. Effects of age and/or weight at slaughter on longissimus dorsi muscle:
Biochemical traits and sensory quality in pigs. Meat Sci., 48, 287-300.

Cho, K.K., Han K.H., Kang S.K, Lee S.H, Choi Y.J., 2002. Applications of cDNA microarray in ruminants. In: $4^{\text {th }}$ Korea-Japan Joint Symp. Rumen Metabolism and Physiology, 2124 Mai 2002, Jeju, Korea, 11p.

Chora M.J., 1996. Etude morphologique du tissu adipeux intramusculaire chez les porcs Large White et Meishan en croissance. Diplôme d'Etudes Approfondies. ENSA Rennes, 27p.

Cianzo D.S., Topel D.G., Whitehurst G.B., Beitz D.C., Self H.L., 1985. Adipose tissue growth and cellularity: changes in bovine adipocyte and number. J. Anim. Sci., 60, 970-976.

Culioli J., Bérri C., Mourot J., 2003. Muscle foods: consumption, composition and quality. Sci. Aliments, 23, 13-34.

Dalle-Zotte A., Ouhayoun J., Parigi-Bini R., Xiccato G., 1996. Effect of age, diet and sex on muscle energy metabolism and on related physicochemical traits in the rabbit. Meat Sci., 43, 15-24.

Damon M., Louveau I., Lefaucheur L., Lebret B., Vincent A., Leroy P., Sanchez M.P., Herpin P., Gondret F., 2006. Number of intramuscular adipocytes and fatty acid binding protein 4 content are significant indicators of intramuscular fat level in crossbred Large White x Duroc pigs. J. Anim. Sci., 84, 1083-1092.

Demeure O., 2000. Le métabolisme des lipides dans le muscle squelettique du porc et ses relations avec la teneur en lipides intramusculaires. Diplôme d'Etudes Approfondies. Université Rennes I, 24p.

Dyck D.J., Peters S.J., Glatz J., Gorski J., Keizer H., Kiens B., Liu S., Richter E.A., Spriet L.L., van der Vusse G.J., Bonen A., 1997. Functional differences in lipid metabolism in resting skeletal muscle of various fiber types. Am. J. Physiol., 272, E340-E351.
Essen-Gustavsson B., Karlsson A., Lundström K, Enfält A.C., 1994. Intramuscular fat and muscle fibre lipid contents in halothane-gene-free pigs fed high or low protein diets and its relation to meat quality. Meat Sci., 38, 269-277.

Fernandez X., Monin G., Talmant A., Mourot J., Lebret B., 1999. Influence of intramuscular fat content on the quality of pig meat. 1 . Composition of the lipid fraction and sensory characteristics of muscle longissimus lumborum. 2. Consumer acceptability of muscle longissimus lumborum. Meat Sci., 53, 59-72.

Geay Y., Bauchart D., Hocquette J.F., Culioli J., 2002. Valeur diététique et qualités sensorielles des viandes de ruminants. Incidence de l'alimentation des animaux. INRA Prod. Anim., 15, 37-52.

Gerbens F., de Koning D.J., Harders F.L., Meuwissen T.H., Janss L.L., Groenen M.A., Veerkamp J.H., Van Arendonk J.A., te Pas M.F., 2000. The effect of adipocyte and heart fatty acid-binding protein genes on intramuscular fat and backfat content in Meishan crossbred pigs. J. Anim. Sci., 78,552-559.

Gerbens F., Verburg F.J., Van Moerkerk H.T., Engel B., Buist W., Veerkamp J.H., te Pas M.F., 2001. Associations of heart and adipocyte fatty acid-binding protein gene expression with intramuscular fat content in pigs. J. Anim. Sci., 79, 347-354.

Gilbert H., Le Roy P., Milan D., Bidanel J.P., 2004. De la détection de QTL à l'analyse des grandes fonctions: l'exemple du chromosome 7 porcin et de la composition corporelle. Journ. Rech. Porcine Fr., 36, 283-288.

Gondret F., Mourot J., Bonneau M., 1998 Comparison of intramuscular adipose tissue cellularity in muscles differing in their lipid content and fibre type composition during rabbit growth. Livest. Prod. Sci., 54, 1-10.

Gondret F., Hocquette J.F., Herpin P., 2001. Teneur en lipides intramusculaires chez le lapin : 
contribution relative des différentes voies métaboliques des tissus musculaires. 9èmes Journ. Rech. Cunicole, Paris, France, 28-29 Novembre, 19-22.

Gondret F., Hocquette J.F., Herpin P., 2004 Age-related relationships between muscle fat content and metabolic traits in growing rabbits. Reprod. Nutr. Dev., 44, 1-16.

Gondret F., Guitton N., Pontrucher F., Trefeu C., Louveau I., 2006. Proteomic analysis evidences regional differences between porcine adipocytes. Congrès de la Société Française d'Electrophorèse et d'Analyse Protéomique, 16-18 Octobre 2006, Saint Malo, France, D5.

Guo, Z, Jensen MD. 1998., Intramuscular fatty acid metabolism evaluated with stable isotopic tracers. J Appl Physiol., 84, 1674-1679.

Hocquette J.F., 2004. Les lipides dans la viande bovine : mythe ou réalité ? Cahiers Agriculture, 13, 1-2.

Hocquette J.F., Graulet B., Olivecrona T., 1998. Lipoprotein lipase activity and mRNA levels in bovine tissues. Comp. Biochem. Physiol. B, 121, 85-96.

Hocquette J.F., Ortigues-Marty I., Damon M., Herpin P., Geay Y., 2000. Métabolisme énergétique des muscles squelettiques chez les animaux producteurs de viande. Prod. Anim., 13, 185200.

Hocquette J.F., Jurie C., Ueda Y., Boulesteix P., Bauchart D., Pethick DW., 2003. The relationship between muscle metabolic pathways and marbling of beef. In: Progress in research on energy and protein metabolism. Souffrant WG. \& Metges CC. (eds). EAAP Publication, 109. Wageningen Pers, Wageningen, The Netherlands, 513-516.

Hocquette J.F., Barnola I., Jurie C., CassarMalek I., Bauchart D., Picard B., Renand G., 2004. Relation entre teneur en lipides intramusculaires et différents marqueurs du type de fibres musculaires chez des taurillons Charolais sélectionnés sur le potentiel de croissance musculaire. Renc. Rech. Rum., 11, 91-94.

Hodgson R.R., Davis G.W., Smith G.C., Savell J.W., Cross HR., 1991. Relationships between pork loin palatability traits and physical characteristics of cooked chops. J. Anim. Sci., 69, 4858-4865.

Janss, L.L.G., van Arendonk J.A.M., Brascamp E.W., 1997. Bayesian statistical analyses for presence of single genes affecting meat quality traits in a crossbred pig population. Genetics, 145, 395-408.

Jiang Z., Kunej T., Michal J.J., Gaskins C.T., Reeves J.J., Busboom J.R., Dove P., Wright R.W., 2005. Significant associations of the mitochondrial transcription factor A polymorphisms with marbling and subcutaneous fat depth in Wagyu x Limousin F2 crosses. Bioch. Biophys. Res. Comm., 334, 516-523.

Kauffman R.G., Safanie A.H., 1967. Influence of porcine muscle structure on its lipid accumulation during growth. J. Food Sci., 32, 283-286.

Kühn C., Leveziel H., Renand G., Goldammer T., Schwerin M., Williams J., 2005. Genetic markers for beef quality. In: Indicators of milk and beef quality. Hocquette J.F., Gigli S. (Eds). EAAP Publication, 112, Wageningen Pers, Wageningen, The Netherlands, 23-32.

Kumar S., Raina P.L., Nair R.B., Amla B.L. 1994. Lipid profiles and fatty acid composition of broiler rabbit meat. J. Food Sci. Technol., 31, 255-258.
Klusek J., Rafai J., Swiderska-Kolacz G., Kolataj A., 1997. The levels of some lipids in the organs of rabbits during different ontogenesis periods. Arch. Tierz. Dummerstorf, 40, 477-482.

Lazo A., Gandemer G., Viau M., Rampon V., Gruaud J., Le Jossec P., Chevillon P., 1994. Evolution de la composition lipidique du muscle long dorsal au cours du développement postsevrage chez trois génotypes porcins. Journ. Rech. Porcine Fr., 26, 175-182.

Leach L.M., Ellis M., Sutton D.S., McKeith F.K., Wilson E.R., 1996. The growth performance, carcass characteristics, and meat quality of halothane carrier and negative pigs. J Anim Sci., 74, 934-943

Lehnert S.A., Wang Y.H., Tan S.H., Reverter A., 2006. Gene expression-based approaches to beef quality research. Austr. J. Exp. Agr., 46, 165-172.

Link B.A., Bray R.W., Cassens R.G., Kauffman R.G., 1970. Lipid deposition in bovine skeletal muscle during growth. J. Anim. Sci., 20, 6-9.

Loussouarn J., 2003. Stratégies dans les filières animales. Prod. Anim., 16, 317-324

Malmfors B., Lundström K., Hansson I., 1978. Fatty acid composition of porcine back fat and muscle lipids as affected by sex, weight, and anatomical location. Swedish J. Agric. Res., 8, $25-38$.

Middleton C.K., Kazala E.C., Lozeman F.J., Hurly P.S., Mir P.S., Bailey D.R.C. Jones S.D.M., Weselake R.J., 1998. Evaluation of diacylglycerol acyltransferase as an indicator of intramuscular fat content in beef cattle. Can J. Anim. Sci., 78, 265-270.

Morrison D.R., Campbell A.M., 1971. Phospholipids as related to total lipid and DNA in light and dark portions of porcine semitendinosus muscle. J. Food Sci., 36, 1103-1104.

Morzel M., Chambon C., Hamelin M., SantéLouthellier V., Sayd T., Monin G., 2004. Proteome changes during pork meat ageing following use of two different pre-slaughter handling procedure. Meat Sci., 67, 696-698.

Mourot J., Kouba M., 1998. Lipogenic enzyme activities in muscles of growing Large White and Meishan pigs. Livest. Prod. Sci., 5 , 127-133.

Mourot J., Hermier D., 2001. Lipids in monogastric animal meat. Reprod. Nutr. Dev., 41, 109118.

Ngapo T.M., Dransfield E., Martin J.F., Magnusson M., Bredahl L., Nute G.R., 2003. Consumer perceptions: pork and pig production. Insights from France, England, Sweden and Denmark. Meat Sci., 66, 125-134.

Nicastro F., Zezza L., Giannico F., Gallo R., Vongia G., 2000. Muscle structure influenced by age on chianina beef. In. Proc. $46^{\text {th }}$ ICoMST. Argentine, 4-I, 436-437.

Pethick D.W., Fergusson D.M., Gardner G.E., Hocquette J.F., Thompson J.M., Werner R., 2005. Muscle metabolism in relation to genotypic and environmental influences on consumer defined quality of red meat. In: Indicators of milk and beef quality. Hocquette JF \& Gigli S (eds). EAAP Publication, 112. Wageningen Pers, Wageningen, The Netherlands. 95-110.

Piot C., Hocquette J.F., Veerkamp J.H., Durand D., Bauchart D., 1999. Effects of dietary coconut oil on fatty acid oxidation capacity of the liver, the heart and skeletal muscles in the preruminant calf. Brit. J. Nutr., 82, 299-308.
Sellier P., 1998. Genetics of meat and carcass traits. In: The Genetics of the Pig. Rothschild M F., and Ruvinsky A. (eds). CAB International, Walingford, UK. 463-510.

Stearns T.M., Beever J.E., Southey B.R., Ellis M., McKeith F.K., Rodriguez-Zas SL., 2005. Evaluation of approaches to detect quantitative trait loci for growth, carcass and meat quality on swine chromosomes 2, 6, 13 and 18. I. Univariate outbred F2 and sib-pair analyses. J. Anim. Sci., 83, 1481-1493.

Sudre K., Leroux C., Pietu G., Cassar-Malek I., Petit E., Listrat A., Auffray C., Picard B., Martin P., Hocquette J.F., 2003. Transcriptome analysis of two bovine muscles during ontogenesis. J. Biochem., 133, 745-756.

Sudre K., Leroux C., Cassar-Malek I. Hocquette J.F., Martin P., 2005. A collection of bovine cDNA probes for gene expression profiling in muscle. Mol. Cell Probes, 19, 61-70.

Talmant A., Monin G., Briand M., Dadet M., Briand Y., 1986. Activities of metabolic and contractile enzymes in 18 bovine muscles. Meat Sci., 18, 23-40.

TePas M.F.W., Cagnazzo M., de Witt AAC., Priem J., Pool M., Davloi R., 2005. Muscle transcriptomes of Duroc and Piétrain pig breeds during prenatal formation of skeletal muscle tissue using microarray technology. Archives Tierz., 48, 141-147.

Valsta L.M., Tapanainen H., Männistö S., 2005. Meat fats in nutrition. Meat Sci., 70, 525-530.

Wakata N., Kawamura Y., Kobayashi M., Araki Y., Kinoshita M., 1990. Histochemical and biochemical studies on the red and white muscle in rabbit. Comp. Biochem. Physiol. B., 97, 543-545.

Wang Y.H., Reverter A., Mannen H., Taniguchi M., Harper G.S., Oyama K., Byrne K.A., Oka A., Tsuji S., Lehnert SA., 2005. Transcriptional profiling of muscle tissue in growing Japanese Black Cattle to identify genes involved with the development of intramuscular fat. Austr. J. Exp. Agr., 45, 809-820.

Wilson B.R., Pearson A.M., Shorland F.B., 1976. Effect of total lipids and phospholipids on warmed-over flavour in red and white muscle from several species as measured by thiobarbituric acid analysis. J. Agric. Food Chem. 24, 7-11.

Wimmers K., Murani E., Schellander K., Ponsuksili S., 2005. Combining QTL and expression analysis: identification of functional positionalcandidate genes for meat quality and carcass traits. Archives Tierz., 48, 23-31.

Wood J.D., Nute G.R., Richardson R.I., Whittington F.M., Southwood O., Plastaow G., Mansbridge R., da Costa N., Chang KC., 2004. Effects of breed, diet, and muscle on fat deposition and eating quality in pigs. Meat Sci., 67, 651-667.

Xiccato G., Parigi-Bini R., Dalle-Zotte A., Crazzolo A. 1994. Effect of age, sex, and transportation on the composition and sensory properties of rabbit meat. In: 40th ICoMST, The Hague, The Netherland.

Zembayashi M., Lunt D.K. 1995. Distribution of intramuscular lipid throughout $\mathrm{M}$. longissimus thoracis et lumborum in Japanese Black, Japanese Shorthorn, Holstein and Japanese Black crossbreds. Meat Sci. 40, 211-216. 


\title{
Résumé
}

La teneur en lipides intramusculaires est une composante importante de la qualité des produits carnés, et en particulier de leur acceptabilité sensorielle. Les facteurs susceptibles de modifier la quantité de lipides dans les muscles de l'animal au moment de son abattage sont multiples, parmi lesquels son génotype, son type sexuel, son âge et son alimentation. Cependant, les déterminismes métaboliques ou géniques de la teneur en lipides intramusculaires restent mal connus. Des travaux récents montrent que l'importance des flux de lipides dans le muscle et l'orientation d'une balance entre de nombreuses voies impliquées dans la lipogenèse des acides gras d'une part et leur oxydation d'autre part, seraient responsables de l'essentiel de la variabilité de la teneur en lipides intramusculaires durant la période postnatale. Les mécanismes précoces qui président au contrôle du nombre d'adipocytes intramusculaires (c'est-à-dire à la prolifération et différenciation cellulaires) seraient majoritairement à l'origine des différences de teneur en lipides intramusculaires en fonction du génotype de l'animal ou de la sélection génétique intra-race. Les approches à haut débit sans a priori, telles que la transcriptomique et la protéomique, devraient prochainement aboutir à l'identification de nouvelles cibles permettant le contrôle de la teneur en lipides intramusculaires, indépendamment de l'adiposité corporelle des animaux.

\begin{abstract}
Muscle lipid content: a complex balance between various metabolic pathways.

Muscle lipid content plays a key role in various quality traits of meat and meat-derived products, including sensory acceptability. Different factors are involved in the variation of muscle lipid content in animals at commercial slaughter, including genotype, gender, age, and feeding. However, the underlying metabolic pathways and(or) the putative involved genes still remain to be clarified. Recent studies have put light on the importance of fatty acid fluxes and metabolic balance between various pathways, rather than the control of one single pathway, to be responsible for variability in muscle lipid content during the postnatal period. Early events that determine the number of intramuscular adipocytes (i.e., proliferation and differentiation of adipose cells) would be rather involved in breed and(or) selection-related differences in muscle lipid content. New targets may be identified in the future using transcriptomic and proteomic approaches, to control muscle lipid content independently of body or carcass fatness.
\end{abstract}

GONDRET F., HOCQUETTE J.-F., 2006. La teneur en lipides de la viande : une balance métabolique complexe. INRA Prod. Anim., 19, 327-338. 
